\title{
Evaluation of Friction Coefficient of Stamping
}

\author{
Emil Evin ${ }^{1 *}$, Stanislav Németh ${ }^{1}$, Marek Vyrostek ${ }^{2}$ \\ ${ }^{1}$ Technical university in Košice, Faculty of Mechanical Engineering, Department of Technologies and Materials, Mäsiarska 74, 04001 Košice \\ 2 Production Manager, Zastrova a.s. SNP 86, 06101 Spišská StaráVes
}

Emil Evin, prof. Ing. CSc. (born 1956) is a professor in the scientific area of Engineering Technologies and Materials, Faculty of Mechanical Engineering at the Technical University in Kosice. He graduated the Faculty of Mechanical Engineering, Technical University of Kosice (1980). He was inaugurated as a professor in 2010 with his work "Verification of numerical simulation of formability of high strength steel sheets" in the field of Mechanical Engineering Technologies and Materials. Prof. Evin pass through the study and lecture stays in Technische Hochshule Zwickau, Technical University in Kielce, Technical Universities in Maribor and Ljubljana; and Technical University in Chemnitz. Long term, his scientific and research activities are oriented to the field of technological prediction of formability of steel sheets with higher strength properties, testing of material properties of steel sheets, simulation of stamping processes, the evaluation of the technical-economic level of production and engineering products. Prof. Evin was the principal investigator of 4 VEGA and 1 APVV projects, co-partner of several national VEGA, APVV and international scientific research projects and dozens of projects for practice. His activities in the Technical University in Košice: Head of Department Automotive production, Deputy of Head of Department, member of Scientific Comitee of Zeszyty Naukowe Instytutu - Proceedings of the Institute of Vehicles Faculty Of Automotive And Construction Machinery Engineering Warsaw University of Technology, a member of the Faculty Commission "Mechanical Engineering Technologies and Materials" Examination Commission for a doctoral level of study at the MTF STU Trnava, expert and judge (reviewer) of the Slovak National Accreditation Service. He is co-author of one monograph, 5 university textbooks, over 180 original scientific papers published in domestic and foreign journals and proceedings.

Stanislav Németh, Ing. Is a PhD. student of the Department of Technologies and Materials at Faculty of Mechanical Engineering at Technical university of Košice. He received B.Sc. and M.Sc. degree in the field of Mechanical Technologies at the same university in 2010 and 2012. His current field of interest is focused on the area of sheet metal forming, such as measurement and evaluation of deformation, simulation of sheet metal forming processes.

\begin{abstract}
This In order to define the friction coefficient the simulator of strip drawn test between flat dies and cup test were applied. To evaluate the coefficient between flat dies the modified Coulumb law was used and for defining the friction at drawing edge of die the modified Ouehler formula was applied. Due to these both evaluation processes it was enabled to point out the difference of friction coefficient values in various contact areas of rolling product and the tool. In his paper there are presented the measurement and evaluation processes of friction coefficient by applying the cup test. For experimental research the following types of materials are suitable: DC 05- extra deep drawable steel sheet, DX 54D - extra deep drawable Zn coated steel sheet, austenitic steel sheet DIN 1.4301.
\end{abstract}

Keywords: Steel sheets, coefficient friction, measurement. 


\section{Introduction}

Formability of steel sheets depends on material properties (mechanical properties, microgeometry of contact surfaces), geometry of die and microgeometry of its contact surfaces, pressure of blank holder, used lubricant, etc. [1 - 4]. Accurate determination of influence of single parameter on technological characteristics is ambiguous because single parameters are changed from one case to another one and their share on formability is changed as well. It is possible to predict the influence of material properties, geometry of die, stamping conditions on sheet formability due to simulation methods which enable us to optimize the utilization of material properties under specific conditions. With the increasing importance of FEM analysis in pre-production, the need for exact values, which serve as input for FEM simulation, is becoming more and more important. These values consist mainly of description of material behaviour and contact conditions. Friction conditions were the subject of the current study [5, 12]. In order to predict formability it is important to define the value of friction coefficient on contact surfaces of die.

Demands for complete information of friction coefficient rose at the moment, when producers of stamping parts started to use simulation methods, new high strength materials, materials with various surface treatments for prediction of formability. Tribological properties of these steel sheets are different from classical ones used for deep drawing. It means that lubricant, which is suitable for classical steel sheets, cannot be appropriate for sheets with special surface treatment [2 - 4].

For determination of friction coefficient for various lubricants and surfaces the model equipment is used the radial strip-drawing friction test or technological tests that simulate the stressing of material in real stamping process $[4,6,13]$.

\section{Experimental Material(s) and Methods}

Most FEM codes use the Coulomb or Amonton friction law:

$$
\tau=f^{*} p
$$

or

$$
T=f^{*} F_{N}
$$

where: $f$ is friction coefficient, $p$ holding pressure,
$T$ friction force, $F_{N}$ holding force, $\alpha$ wrapping angle of the drawing edge of die.

This friction coefficient is normally obtained by experiment, which has to have the following characteristics: First, model experiment conditions should be similar to real deep-drawing situation. Second, the determination of the friction coefficient has to be enabled both with and without the use of a model plastic deformation on the material behaviour. Finally, the friction coefficient must be obtained in a single experiment [5]. Stamping processes (deep drawing, stretching, and bending) are characterized by various types of contacts between the steel sheet and contact areas of die - Fig. 1a, b, c. According to these main types of models we are able to analyze the majority of contacts for operations of stamping.

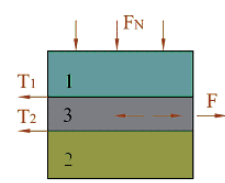

a)
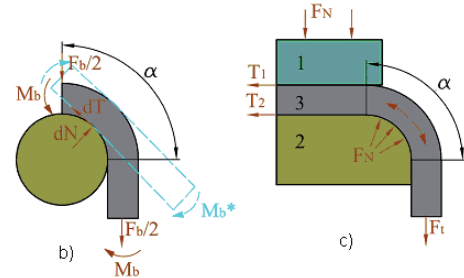

Fig. 1: Key features of diverse contacts involved in metal forming processes and their effect on forces 1-tool (blank holder), 2 - tool (die), 3 - steel sheet, Mb - bending moment, Fb-bending force, $a$-wrapping angle of the drawing edge of die.

In Fig. 1a the contact between two flat areas is shown. The steel sheet strip is moved between two contact surfaces of die which are separated by lubricant. In Fig. 1b there is shown the steel sheet strip bending model at the drawing edge of die and its sliding through the drawing edge of die. In Fig. 1c the model presents the final effect of friction forces. (Fig. 1a and 1b), the steel sheet strip is sliding between plane clams, is bent and at the same time it slides through the drawing edge of die.

The following types of materials were used for experimental research - Table 1: DC 05 - extra deep drawable steel sheet, suitable for complex large area stamped parts of auto body panels and other types of stamped parts (marked as A), DX 54D - extra deep drawable $\mathrm{Zn}$ coated steel sheet, suitable for complex large area stamped parts of auto body panels and other stamped parts (marked as B), Austenitic stainless steel sheet (STN 17241 or DIN 1.4301, marked as C), suitable for cold forming by 
Table 1: Material properties of tested materials [7].

\begin{tabular}{|c|c|c|c|c|c|c|}
\hline Material & $\begin{array}{l}\text { Rolling } \\
\text { direction }\end{array}$ & $\begin{array}{l}\text { Yield strength } \\
0,2 \% \mathrm{YS} \text { [MPa] }\end{array}$ & $\begin{array}{l}\text { Ultimate tensile } \\
\text { strength UTS [MPa] }\end{array}$ & $\begin{array}{l}\text { Material constant } \\
\mathrm{K}[\mathrm{MPa}]\end{array}$ & $\begin{array}{l}\text { Strain hardening } \\
\text { exponent } \mathbf{n}\end{array}$ & $\begin{array}{l}\text { Normal anisotropy } \\
\text { values } \mathbf{r 0}, \mathbf{r} 45, \mathbf{r}_{90}\end{array}$ \\
\hline \multirow{3}{*}{ A } & $0^{\circ}$ & 164 & 299 & 505 & 0.23 & 1.9 \\
\hline & $45^{\circ}$ & 172 & 309 & 531 & 0.219 & 1.5 \\
\hline & $90^{\circ}$ & 166 & 296 & 511 & 0.221 & 2.2 \\
\hline \multicolumn{2}{|c|}{ Average values } & 168 & 303 & 515 & 0.222 & 1.77 \\
\hline \multirow{3}{*}{ B } & $0^{\circ}$ & 170 & 292 & 492 & 0.208 & 1.98 \\
\hline & $45^{\circ}$ & 180 & 304 & 503 & 0.203 & 1.04 \\
\hline & $90^{\circ}$ & 184 & 297 & 487 & 0.215 & 1.59 \\
\hline \multicolumn{2}{|c|}{ Average values } & 182 & 300 & 497 & 0.207 & 1.59 \\
\hline \multirow{3}{*}{ C } & $0^{\circ}$ & 267 & 634 & 1523 & 0.517 & 0.98 \\
\hline & $45^{\circ}$ & 262 & 615 & 1469 & 0.519 & 1.03 \\
\hline & $90^{\circ}$ & 273 & 629 & 1491 & 0.515 & 0.99 \\
\hline \multicolumn{2}{|c|}{ Average values } & 267 & 625 & 1494 & 0.517 & 1.01 \\
\hline
\end{tabular}

stretching.

Values of surface micro geometry Ra (arithmetical mean deviation of the assessed profile were: material A $1.09 \mu \mathrm{m}$, material B $1.25 \mu \mathrm{m}$, material $\mathrm{C} 0.16 \mu \mathrm{m})$ of tested materials in the direction $90^{\circ}$ due to rolling direction were determined by the Hommel Tester T 1000 equipment. Materials properties are given in Table 1.

\section{Results and Discussion}

The friction simulator Fig. 2 was used for study of the friction ratios during stamping process. The simulator enables the stress modelling of flat areas and also of curved ones. These contact processes can be investigated separately or in their combinations. The simulator may be applied in both, the vertical or horizontal positions. In horizontal position the roller can rotate or its movement can be blocked - Fig. 2. If we assume that for the numerical simulation of stamping processes it is sufficient to define the friction coefficient with uncertainty \pm 0.005 , then the friction coefficient in rolling bearings will be ignored (friction coefficient in rolling bearings is approximately 0.0015 [8]).

If the movement of roller is not blocked then we will model the stressing of contact areas of dies under blank holder between flat surfaces. In that case when the turning of roller is blocked we will model the stressing of curved contact areas on the drawing edge of die. The simulator is equipped with dynamometer of drawing and blank holding forces.

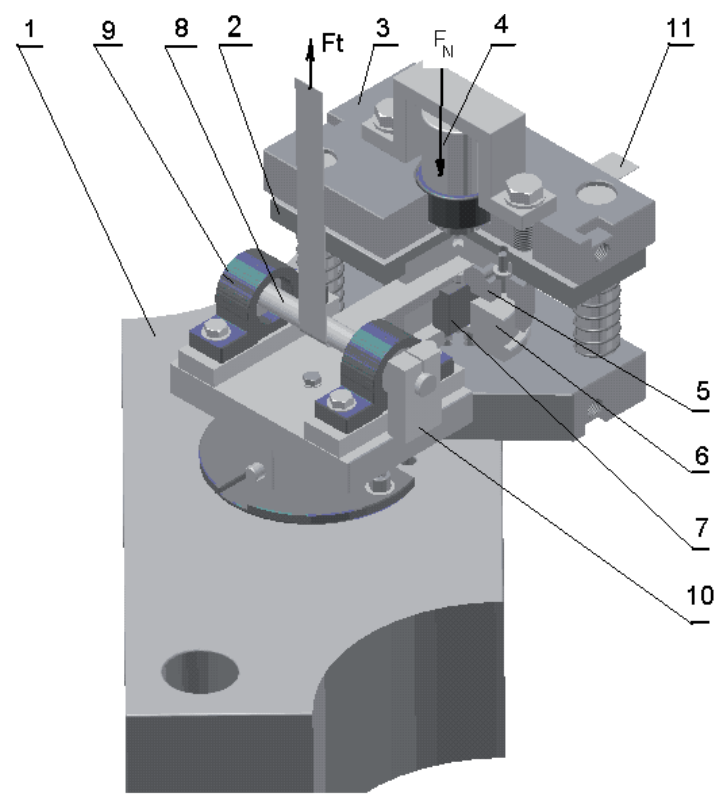

Fig. 2: The 3-D model of friction simulator - strip drawn test. 1 - base, 2 - clamping mechanism, 3 - upper plate, 4 - hydraulic clamping cylinder, 5 - upper grip mechanism, 6- lower grip mechanism, 7 - clamping force dynamometer, 8 - roller, 9 - ball bearings, 10 - brake mechanisms of the roller, 11 - steel strip sheet.

Records of drawing and blank holding forces for the strip drawing by rotating roller are shown in Fig 3. Similar records were obtained also for strip drawing between flat grips and applied materials B and $\mathrm{C}$. 


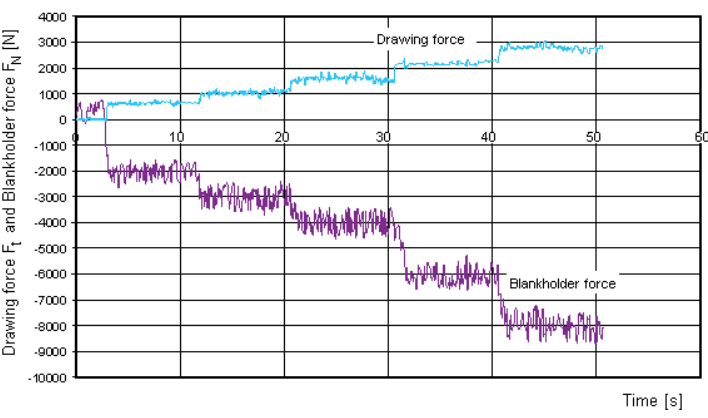

Fig. 3: Record of drawing force and blank holder force.

\section{Case 1: Simulations conducted with a rotating roller.}

Stress of contact areas under the blank holder was modelled by simulator in horizontal position and with rotating roller - Fig. 1a. Drawing conditions were: holding forces: 2000, 3000, 4000, 6000, $8000 \mathrm{~N}$, speed of the strip drawing: $v=10 \mathrm{~mm} / \mathrm{s}$, roughness of upper grip and lower grip $\mathrm{Ra}=0.4 \mu \mathrm{m}$, roughness of roller $\mathrm{Ra}=0.4 \mu \mathrm{m}$. The lubricant was spotted on steel sheet strip Ferrocoat cca $2 \mathrm{~g} / \mathrm{m}^{2}$. Ferrocoat A 6130 is the mixture of mineral oils, synthetic esters and additives with kinematical viscosity $26 \mathrm{~mm}^{2} / \mathrm{s}$ at temperature $40^{\circ} \mathrm{C}$.

Assessing the friction forces in different conditions as presented in Fig. 1 we have assumed that drawing force F - Fig. 1a:

$$
F=T_{1}+T_{2}=T_{1,2}=2 f_{1,2} F_{N}
$$

where: $T_{1,2}$ is friction forces between flat dies and $f_{l, 2}$ friction coefficient between flat dies. Figure $1 \mathrm{~b}$ the steel sheet strip is sliding through the drawing edge of die (the rotation of roller is blocked) and assuming the steel sheet strip is sliding through the drawing edge then will be:

$T_{3}=e^{\alpha, f_{3}} T_{1,2}$

where: $T_{3}$ is friction force at drawing rolling area, $f_{3}$ friction coefficient at drawing rolling area, a wrapping angle of the drawing edge of die. The final effect friction forces (Fig. 1a and 1 b), the sheet metal strip is sliding between clams and through drawing edge of die / roller/ then the final drawing force necessary for strip bending and overpowering of friction forces will be:

$F_{t}=e^{\alpha f} T_{1,2}$
If we suppose that in the case of simulator with rotating roller the friction coefficient on the drawing edge is $f_{3}=0$, then the drawing force will be:

$F_{t(f 3=0)}=e^{\alpha / 3} T_{1,2}+F_{b}$

After subtraction of bending force:

$F_{t(f 3=0)}-F_{b}=T_{1,2}$

then we are able to calculate the friction coefficient by modified term (2):

$f_{1,2}=\frac{T_{1,2}}{2 F_{N}}$

where: $F_{t}$ is drawing force, $F_{b}$ bending force, $F_{N}$ holding force, resp. blank holding force, $F_{t(f 3=0)}$ drawing force generated by a rotating roller.

In Table 2 there are listed adjusted values of holding forces $F_{N}$, drawing forces $F_{t}$, friction force $T_{1,2}$ between the steel sheet and the blank holder (upper grip) and also between the steel sheet and the die (lower grip). The bending force was evaluated according to five measurements of each material. The sheet metal strip was being tensioned during holding force effect $F_{N}=20000 \mathrm{~N}$. At holding force $F_{N}=20000 \mathrm{~N}$ there was no sign of drawingout of steel sheet strip from clamps. At the moment of completion of bending process there has occurred a plastic deformation of sheet metal strip (it has been lengthened) and there was a rapid force increase. The bending force $F_{b}$ was evaluated at this moment.

\section{Case 2: Simulations conducted with a stationary roller.}

Stress of contact areas under the blankholder and on drawing edge of die Figure $1 \mathrm{~b}$ was modelled by simulator in horizontal position and with blocked roller - Fig. 2. If we suppose that in the case of simulator with blocked roller the friction coefficient on the drawing edge is $\mathrm{f} 3>3$, then we are able to calculate the drawing force by Ouehler formula:

$F_{t(f 3>3)}=e^{\alpha / 3} T_{1,2}+F_{b}$

According to difference between drawing force with blocked roller and drawing force with rolling roller we obtain the contribution of friction element of force on the drawing edge of die. 
Table 2: Measured values of drawing and holding forces on drawing edge of die (conditions: material A, lubricant Ferrocoat, strip drawing speed $10 \mathrm{~mm} / \mathrm{s}$ ).

\begin{tabular}{|c|c|c|c|c|c|c|}
\hline \multirow[b]{2}{*}{ Material } & \multirow{2}{*}{$\begin{array}{l}\text { FN [N] } \\
\text { P [MPa] }\end{array}$} & \multicolumn{3}{|c|}{ Drawing forces [N] } & \multicolumn{2}{|c|}{ Friction coefficients } \\
\hline & & $F_{t(f 3=0)}$ & $\begin{array}{l}F_{t(f 3>0)} \\
E_{q} .11\end{array}$ & $\begin{array}{c}F t(f 3=0)-F b \\
E q .15\end{array}$ & $\begin{array}{c}f, 2 \\
\text { Eq. } 8\end{array}$ & $\begin{array}{c}f_{3} \\
E q \cdot 11\end{array}$ \\
\hline \multirow{5}{*}{ A } & $\begin{array}{c}2000 \\
-\end{array}$ & 658 & 716 & 475 & - & - \\
\hline & $\begin{array}{c}3000 \\
2\end{array}$ & 945 & 1076 & 758 & 0.12 & 0.10 \\
\hline & $\begin{array}{c}4000 \\
2.7\end{array}$ & 1154 & 1350 & 950 & 0.12 & 0.11 \\
\hline & $\begin{array}{c}6000 \\
4\end{array}$ & 1640 & 1857 & 1366 & 0.11 & 0.10 \\
\hline & $\begin{array}{c}8000 \\
5.3\end{array}$ & 2011 & 2282 & 1824 & 0.11 & 0.09 \\
\hline \multirow{5}{*}{ B } & $\begin{array}{c}2000 \\
-\end{array}$ & 531 & 600 & 394 & - & - \\
\hline & $\begin{array}{c}3000 \\
2\end{array}$ & 868 & 971 & 735 & 0.12 & 0.085 \\
\hline & $\begin{array}{c}4000 \\
2.7\end{array}$ & 996 & 1168 & 876 & 0.11 & 0.115 \\
\hline & $\begin{array}{c}6000 \\
4\end{array}$ & 1384 & 1658 & 1240 & 0.10 & 0.125 \\
\hline & $\begin{array}{c}8000 \\
5.3 \\
\end{array}$ & 1865 & 2152 & 1748 & 0.11 & 0.095 \\
\hline \multirow{5}{*}{ C } & $\begin{array}{c}2000 \\
1.3\end{array}$ & 1383 & 1560 & 867 & - & - \\
\hline & $\begin{array}{c}3000 \\
2\end{array}$ & 1781 & 1950 & 1203 & 0.20 & 0.08 \\
\hline & $\begin{array}{c}4000 \\
2.7 \\
\end{array}$ & 2120 & 2417 & 1520 & 0.19 & 0.11 \\
\hline & $\begin{array}{c}6000 \\
4\end{array}$ & 2895 & 3095 & 2390 & 0.2 & 0.05 \\
\hline & $\begin{array}{c}8000 \\
5.3\end{array}$ & 3790 & 4282 & 3299 & 0.21 & 0.09 \\
\hline
\end{tabular}

$F_{t(f 3>0)}-F_{t(f 3=0)}=\left(e^{\alpha f 3}-1\right) T_{1,2}$

(10)

If the wrapping angle is $\alpha=90^{\circ}$ or $\pi / 2$, then the friction coefficient $f 3$ on drawing edge of die will be:

$f_{3}=\ln \left(\frac{F_{t, f 3>0}-F_{t, f 3=0}}{T_{12}}+1\right) \frac{2}{\pi}$

where: $\mathrm{F}_{\mathrm{t}(\mathrm{f} 3=0)}$ is drawing force generated by a rotating roller, $\mathrm{F}_{\mathrm{t}(\mathrm{f} 3>0)}$ drawing force generated by a stationery roller, $f 3$ friction coefficient at drawing
From Fig. 4, it is evident that drawing forces

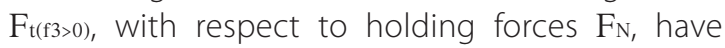
showed linear trends for all three experimental 'A to C'steel work-piece materials.

$$
F_{t(f 3>0)}=\text { Intercept }+F_{N}(\text { Slope })
$$

Intercepts and slopes were positive meaning. This means that drawing forces had been increasing with increasing holding forces. Also, slopes were significant at $\mathrm{R}^{2}=0.99$, see Fig. 4 . The friction coefficient is equal to half of the slope value 
$f=\frac{\text { Slope }}{2}$

as shown Table 3:

Table 3: Averaged values of friction coefficients for materials $A, B$ and $C$ in a constant drawing speed of $10 \mathrm{~mm} / \mathrm{s}$.

\section{MaterialA Material B MaterialC}

\begin{tabular}{|l|l|l|l|}
\hline $\boldsymbol{f}_{1,2}$ - Eq. $\mathbf{8}$ & 0.12 & 0.11 & 0.20 \\
\hline $\boldsymbol{f}_{\mathbf{3}}$ - Eq. $\mathbf{1 1}$ & 0.10 & 0.105 & 0.08 \\
\hline $\boldsymbol{f}_{\text {slope } \text { - Eq. } \mathbf{1 3}}$ & 0.13 & 0.12 & 0.22 \\
\hline
\end{tabular}

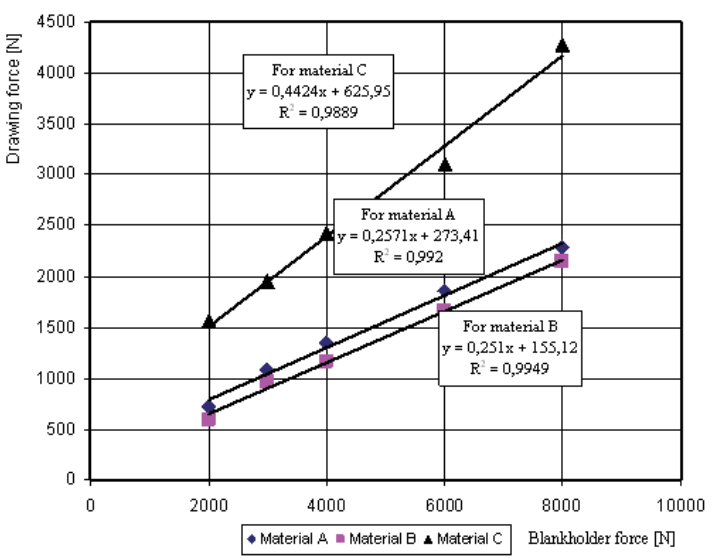

Fig. 4: Depends of experimental drawing forces on blank holder forces by strip drawn test for materials $A, B$ and $C$.

\section{Case 3: Cup-test.}

Cup-test was performed on hydraulic machine RM-501, LVH-1. Cup-test conditions were: diameter of punch with flat bottom $\mathrm{d}=32.85 \mathrm{~mm}$, radius of drawing edge of the punch with flat bottom $\mathrm{r}_{\mathrm{p}}=4.5 \mathrm{~mm}$, radius of drawing edge of the die $\mathrm{r}_{\mathrm{d}}=4.5 \mathrm{~mm}$, roughness of die $\mathrm{Ra}=0.4 \mu \mathrm{m}$, roughness of blank holder $\mathrm{Ra}=0.4 \mu \mathrm{m}$, steel sheet thickness $\mathrm{s}_{0}=0.78 \mathrm{~mm}$, amount of the lubricant $2 \mathrm{~g} / \mathrm{m}^{2}$ - Fig. 5. The blank steel sheets with the diameter $\mathrm{D}_{0}=60 \mathrm{~mm}$ were used for modelling of different friction combinations. Also values of blank holder forces were adjusted: 2 kN, 5 kN, 10 kN, 20 kN and

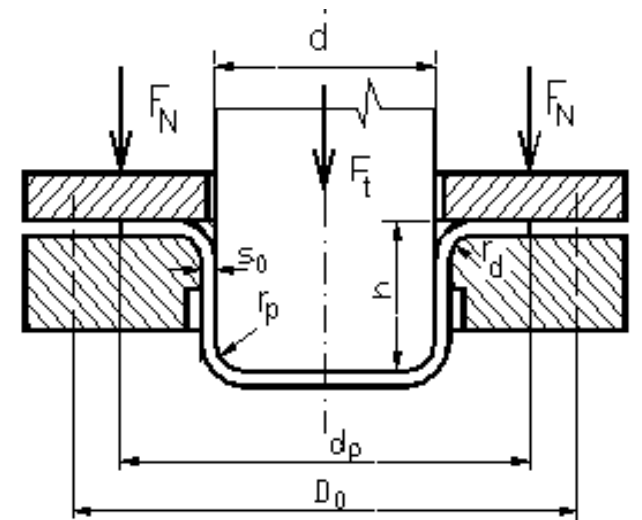

Fig. 5: Scheme of the experimental cup test.

$30 \mathrm{kN}$. The determination of value of drawing force at constant drawing conditions was done using of five specimens.

\section{Conclusion}

The aim of this paper was to highlight the fact that in the production of sheet metal presswork the friction coefficient is not always constant in different contact surfaces between sheet metal and moulding tool. Furthermore there were presented various assessment methods of friction coefficient and verification of friction model implemented in program files of numerical simulation. We can summarize the obtained results as follows:

1. The friction simulator (strip drawn test) and cup test were used for determination of the friction coefficient. At both tests the highest values of friction coefficients were obtained with material $C$ DIN 1.4301. This material had the lowest value $\mathrm{Ra}=$ $0.16 \mu \mathrm{m}$. Ratio between real and ideal contact area was low. The lubricant had no place to adhere and make bindings with the surface of stamped part.

2. Results of comparison of friction coefficient values $\mathrm{fm}-\mathrm{fp}=\Delta f$ evaluated due to dependencies of experimentally measured and calculated drawing forces values at holding forces highlight at coefficient values cca 0.1 that there is a little difference $(\Delta f=0.015)$ but at higher values of fric-

Table 4: Results from regression analysis of the deep drawing forces with respect to the holding forces.

\begin{tabular}{|c|c|c|c|c|c|c|c|}
\hline Material & Intercept & P-value & Slope & P-value & $\mathbf{R}^{2}$ & $f_{m}$ and $f_{c}$ & $\Delta f$ \\
\hline 'A' (Experimental values $f_{m}$ ) & 18.88 & $3.04 \mathrm{E}-10$ & 0.20 & $1.06 \mathrm{E}-06$ & 0.99 & 0.10 & 0.015 \\
\hline 'B' (Experimental values $f_{m}$ ) & 17.54 & $1.41 \mathrm{E}-09$ & 0.21 & $2.8 \mathrm{E}-06$ & 0.99 & 0.105 & 0.015 \\
\hline${ }^{\prime} C^{\prime}$ (Experimental values $f_{m}$ ) & 27.50 & $2.13 \mathrm{E}-10$ & 0.39 & $1.88 \mathrm{E}-07$ & 0.99 & 0.195 & 0.035 \\
\hline
\end{tabular}


tion coefficients cca 0.2 there is a bigger difference $(\Delta f=0.035)$. Differences of $\Delta f$ in range from 0.105 to 0.035 do not have significant influence on drawing forces and also on the change of thickness of drawn part wall.

3. The obtained results show also the fact that by combination of both, the simulator and cup test, values of friction coefficients for various combinations of stamping conditions can be determined.

4. During the determination of values of friction coefficients for program file of simulation, it is important to define values of friction coefficients for every single contact area separately.

\section{Acknowledgments}

This work was completed in the framework of the project APVV-0682-11 and national Grant project VEGA 1/0824/12.

\section{References}

[1] Doege E, Droder B, Greisbach B (1997) On development of new characteristic value for the evaluation of sheet metal formability. Journal of Materials Processing Technology 71:152-159.

[2] Lange K (1990) Umformtechnik - Blechbearbeitung. Springer/Nerlag, Berlin.

[3] Mahrenholtz O, Bontcheva N, (2005) Influence of surface roughness on friction during metal forming processes. Journal of Materials Processing Technology 159:9-16.

[4] Hrivňák, A, Evin E (2004) Formability of steel sheets. Elfa, Košice.

[5] Sniekers RJJM, Smits HAA (1997) Experimental set-up and data processing of the radial strip-drawing friction test. Journal of Materials Processing Technology 66:216-223.

[6] Evin E, Hrivňák A, Tkáčová J (2001) Measurement and evaluation of friction ratios at deep drawing. Journal for Technology of Plasticity 26:81-88.

[7] Evin E, Pinko P, Kmec (2006), Numerical simulation of deepdrawing process and coefficient of friction. Manufacturing Engineering 5:18-22.

[8] Becka J (1997) Tribologie. CVUT, Praha.

[9] Audy J, Evin E (2008) Evaluation of forces and work generated by uncoated and TiN coated tools in backward extrusion of cylindrical - low carbon steel - slugs. Journal Forging 31:7-15.

[10] Audy J, Evin E (2008) Study of friction conditions in deep drawing process with TiN coated tools, Journal Forging. 33:117-118.

[11] Audy J, Evin E (2008) Exploring efficiency of tool coating via deep drawing of cylindrical cups. MMScience Journal 2:2023.

[12] Zhenyu H, Vollertsen, F (2004) A new friction test method. Journal for Technology of Plasticity 29:1-9.

[13] Pradeep Menezes L, Kumar K, Kishore and Satish V (209) Influence of friction during forming processes - a study using a numerical simulation technique. The International Journa of Advanced Manufacturing Technology.

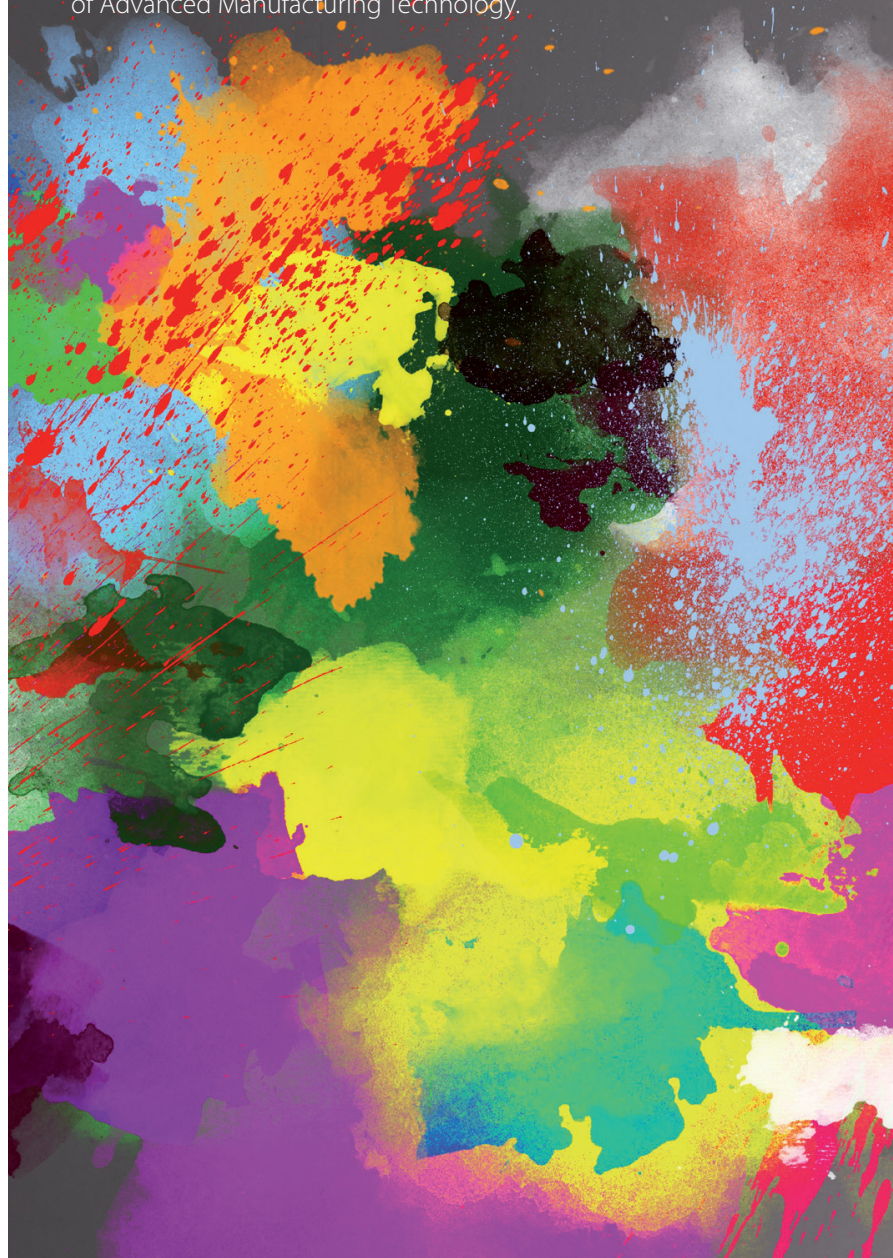




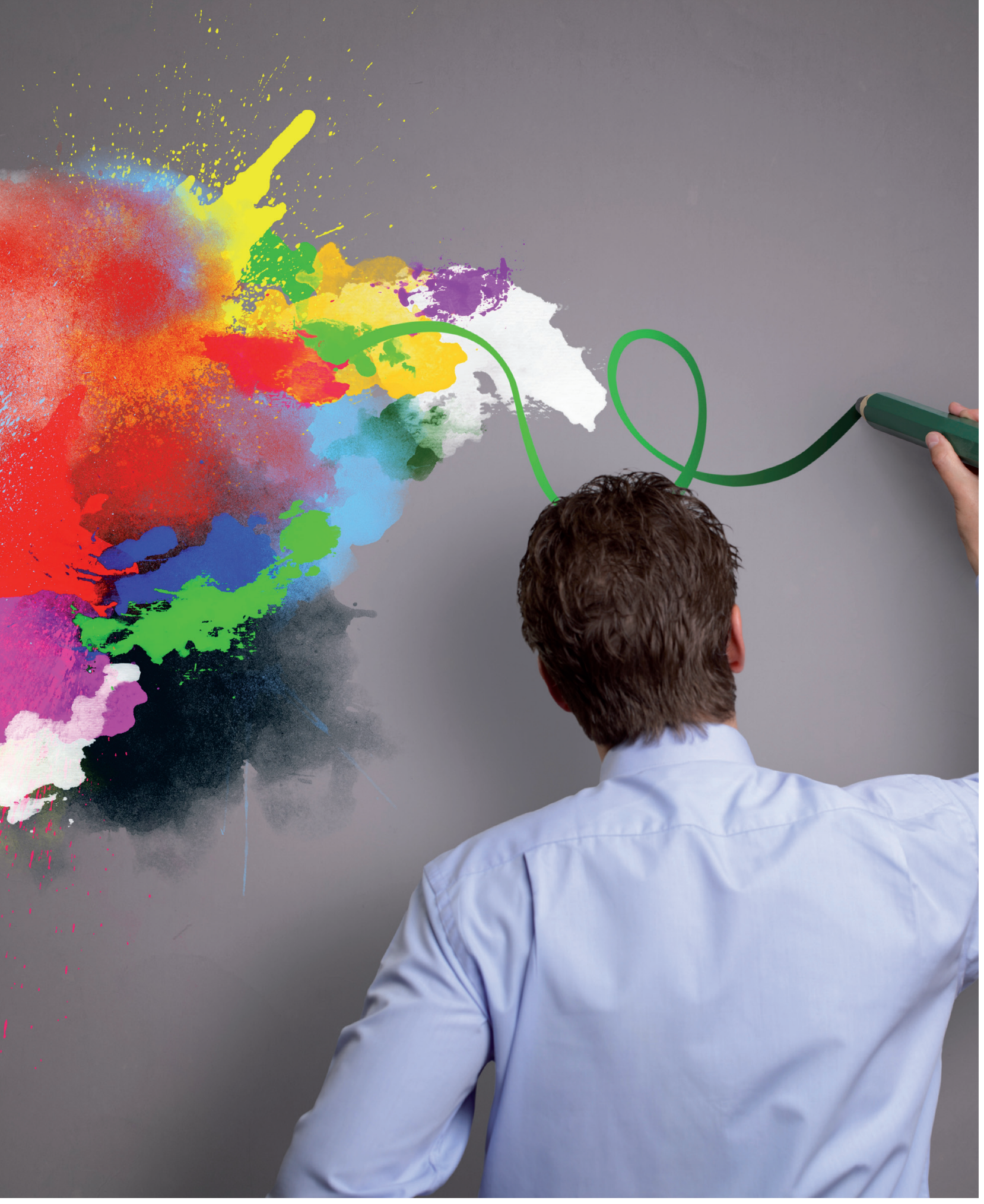

